\title{
Activation of Renal Cortical Adenylate Cyclase by Circulating Immunoreactive Parathyroid Hormone Fragments
}

\author{
Janet M. Canterbury, Gerald S. Levey, and Eric Reiss \\ From the Division of Endocrinology and Metabolism, Department of Medicine, \\ University of Miami School of Medicine, Miami, Florida, 33152 and the \\ Department of Biology, Illinois Institute of Technology, \\ Chicago, Illinois 60616
}

\begin{abstract}
A в S.T R A C T Three distinct immunoreactive species of parathyroid hormone (PTH) are present in human serum. One has an estimated mol wt of 9,500 and probably represents glandular hormone, the second $7,000-7,500 \mathrm{~mol} \mathrm{wt}$, and the third 4,500-5,000 mol wt. In order to assess the biological activity of these circulating forms of PTH, we determined their ability to activate renal cortical adenylate cyclase. The 9,500 mol wt and 4,500-5,000 mol wt fractions produced four- to sixfold increases in cyclic $3^{\prime}, 5^{\prime}$-AMP accumulation above control; the 7,000-7,500 mol wt fraction was inactive. None of the fragments had any effects on phosphodiesterase activity. Antiserum to bovine PTH did not block the activation of adenylate cyclase by either the fragments or bovine PTH. The data suggest that a large proportion of circulating immunoreactive human PTH is biologically active and that the biologically and immunologically active sites of the hormone are distinct.
\end{abstract}

\section{INTRODUCTION}

We have recently demonstrated the presence of three distinct immunoreactive species of parathyroid hormone $(\mathrm{PTH})^{1}$ in human serum (1). These species differ in mol wt, immunological characteristics, and kinetic properties. One has an estimated mol wt of 9,500, similar to that for glandular PTH, the second, 7,000-7,500 mol wt and the third, 4,500-5,000 mol wt. The existence of

This work represents Ms. Canterbury's partial fulfillment of the research requirements for the Ph.D. degree at Illinois Institute of Technology. Dr. Levey is an investigator, Howard Hughes Medical Institute.

Received for publication 27 September 1972 and in revised form 6 November 1972.

${ }^{1}$ Abbreviation used in this paper: $\mathrm{PTH}$, parathyroid hormone. immunoreactive fragments of circulating PTH has been demonstrated in two other laboratories $(2,3)$, but there is disagreement whether these circulating fragments have biological activity $(4,5)$.

Chase and Aurbach (6) demonstrated that PTH activates adenylate cyclase in renal cortex and increases the urinary excretion of adenosine $3^{\prime}, 5^{\prime}$-monophosphate (cyclic AMP) (7). They postulated that the activation of adenylate cyclase with its resultant increase in intracellular cyclic AMP mediates the effects of PTH on the kidney.

In order to assess the biological activity of circulating PTH fragments, we determined their ability to activate renal cortical adenylate cyclase.

\section{METHODS}

Preparation and assay of renal cortical adenylate cyclase. Rats were anesthetized with pentobarbitol and the kidneys were rapidly removed. The cortex was dissected from medullary tissue with a razor blade and minced. Approximately $200-300 \mathrm{mg}$ of cortical tissue was homogenized in $4.5 \mathrm{ml}$ of cold, $0.25 \mathrm{M}$ sucrose. The homogenate was centrifuged at $12,000 \mathrm{~g}$ for $10 \mathrm{~min}$ at $4^{\circ} \mathrm{C}$, and the supernatant fluid was decanted; the particles were washed with cold $0.25 \mathrm{M}$ sucrose, resuspended, and recentrifuged at $12,000 \mathrm{~g}$ for $10 \mathrm{~min}$. The washed particles were then resuspended and rehomogenized in the cold $0.25 \mathrm{M}$ sucrose. Protein was determined by the method of Lowry, Rosebrough, Farr, and Randall (8), and adenylate cyclase was assessed by the method of Krishna, Weiss, and Brodie (9). The particulate fraction containing $0.09-0.12 \mathrm{mg}$ protein was incubated at $37^{\circ} \mathrm{C}$ for $15 \mathrm{~min}$ with $2.5 \mathrm{mM}$ ATP, $\alpha^{32} \mathrm{P}$-ATP, $3.0-3.5 \times 10^{\circ}$ cpm; theophylline, $8 \mathrm{mM}$; $\mathrm{MgCl}_{2} 3.2 \mathrm{mM}$; Tris- $\mathrm{HCl}, 21$ $\mathrm{mM}, \mathrm{pH} 7.7$; phosphoenolpyruvate, $0.9 \mathrm{mM}$; pyruvate kinase, $0.02 \mathrm{mg} / \mathrm{ml}$; potassium chloride $26 \mathrm{mM}$; human serum albumin $0.8 \mathrm{mg} / \mathrm{ml}$; and varying amounts of bovine PTH, immunoreactive fragments, or the equivalent amount of fractionated hypoparathyroid serum, as noted in the text. The diluent for all PTH fractions and for bovine PTH was $0.01 \mathrm{~N}$ acetic acid. The total volume of the incubation 
mixture was $0.065 \mathrm{ml}$. The accumulation of ${ }^{32} P$-cyclic $3^{\prime}, 5^{\prime}-$ AMP was determined as previously described (10). Boiled enzyme controls contained $10 \mathrm{pmol}$ of ${ }^{32} P$-cyclic $3^{\prime}, 5^{\prime}$-AMP, which was subtracted from the values shown in the results.

Preparation of parathyroid fragments from human serum. PTH fractions were derived from the sera of 23 patients with primary hyperparathyroidism. In each of five experiments, the sera from three to five patients were pooled (2$5 \mathrm{ml}$ per patient), concentrated by Amicon filtration (Amicon Corp., Lexington, Mass.), and fractionated on Bio gel P-10 (Bio-Rad Laboratories, Richmond, Calif.), as previously described (1). Eluted fractions were assayed by radioimmunoassay using a single antiserum, $\mathrm{CH}-824$ (11). ${ }^{131}$ I-bovine PTH served as a marker for glandular PTH. Three distinct immunoassayable peaks emerged with each filtration in a highly reproducible pattern with estimated mol wt of 9,500, 7,000-7,500, and 4,500-5,000. Narrow cuts from the top of each peak were made for pooling of individual immunoreactive peaks. The pooled peaks were concentrated 10 -fold by partial lyophilization and again 10-fold by use of VirTis Bio-dryer (VirTis Co., Inc., Gardiner, N. Y.). The latter procedure was required to remove most of the ammonium acetate, the eluent buffer. The final volume of all concentrated PTH fractions was $0.2 \mathrm{ml}$.

For control fractions, the sera from 11 hypoparathyroid patients were pooled, concentrated, and fractionated in a manner identical to that used for hyperparathyroid sera. Immunoassayable PTH could not be detected in any of these samples. Pools were made of the fractions where the three immunoassayable peaks would be expected to elute in the gel chromotography procedure using hyperparathyroid serum.

Blocking experiments were performed by preincubating $0.1 \mathrm{ml}$ of the synthetic $N$-terminal peptide (1-34 amino acids) of bovine $\mathrm{PTH}^{2}(750 \mu \mathrm{g} / \mathrm{ml})$ with $0.1 \mathrm{ml}$ of the antiserum $\mathrm{CH}-824$ (1:50,000) for 3 days before immunoassay of the hyperparathyroid peaks.

\section{RESULTS}

Effects of PTH fragments on activation of adenylate cyclase. The effects of the three immunoreactive peaks on the activation of adenylate cyclase in a particulate preparation of rat renal cortex is shown in Table I. Peaks I and III produced four- to sixfold increases above control values. In contrast, peak II did not activate adenylate cyclase. Concentration-response curves for peaks I and III and for purified bovine PTH are shown in Fig. 1. The responses are parallel. It would appear from these curves that $25 \mu \mathrm{l}$ of peaks I and III from hyperparathyroid sera contained approximately the equivalent of $5 \mu \mathrm{g} / \mathrm{ml}$ of bovine PTH.

Effects of bovine PTH antibody on the activation of adenylate cyclase by peaks $I$ and III. The effect of antiserum to bovine PTH on the accumulation of cyclic AMP produced by peaks I and III and by purified bovine PTH was examined (Table II). Preincubation with PTH antibody failed to abolish the activation by any of the stimulations, including that of bovine PTH. Failure to abolish the activation by any of the agonists

\footnotetext{
${ }^{2}$ Synthetic PTH peptide obtained from Beckman Instruments, Bioproducts Department, Palo Alto, Calif.
}

TABLE

Effects of Fractionated Human Parathyroid Hormone of Rat Renal Cortex Adenylate Cyclase

\begin{tabular}{lcc}
\hline & $\begin{array}{c}\text { Cyclic 3', 5'-AMP } \\
\text { accumulated/mg } \\
\text { protein per } \\
15 \text { min* }\end{array}$ & P value \\
\hline & pmol & \\
Control $\ddagger$ & $80 \pm 20$ & $<0.01$ \\
Peak I & $344 \pm 56$ & NS \\
Control & $64 \pm 8$ & \\
Peak II & $80 \pm 16$ & $<0.01$ \\
Control & $64 \pm 12$ & \\
Peak III & $384 \pm 32$ & \\
\hline
\end{tabular}

* Each value represents the mean $\pm \mathrm{SE}$ of four samples. ¥ Control incubations contained equivalent amounts (25 1) of fractionated hypoparathyroid serum. All complete incubation mixtures contained $0.12 \mathrm{mg}$ protein.

was also encountered when antibody was added directly to the adenylate cyclase incubation mixture.

Under the conditions of these experiments, antigen was bound to antibody, as shown by immunoassay. Trace I ${ }^{121}$-labeled bovine PTH was added to a sample of the incubation mixture at the time of the in vitro assay, and the incubation was continued for another $24 \mathrm{~h}$. The antibody-bound to free hormone ratio was 4.0 with trace hormone and antibody only, 0.8 with

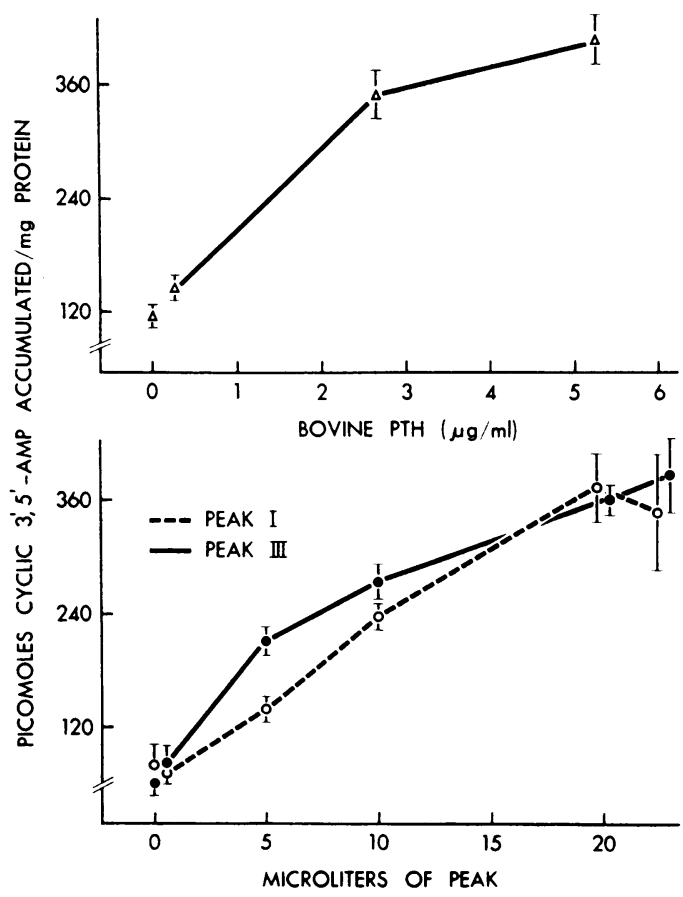

Figure 1 Concentration-response curves for bovine PTH (top) and immunoreactive fragments (bottom). Each value represents mean $\pm \mathrm{SE}$ of four samples.

Parathyroid Hormone and Adenylate Cyclase 525 
peak I, 1.3 with peak II, and 0.01 with purified bovine PTH.

Effect on phosphodiesterase activity. Since inhibition of this enzyme could account for an increase in cyclic AMP accumulation, we examined the effect of peaks I and III on the phosphodiesterase activity. None was observed: control 5.4, peak I, 5.4; peak III, $5.3 \mathrm{nmol}$ cyclic AMP hydrolyzed per milligrams protein per 10 $\min$.

Immunological competition between human fragments and synthetic bovine fragment. As shown in Table III, preincubation of the biologically active $N$-terminal synthetic bovine peptide fragment, 1-34, with antibovine PTH sera resulted in significant decrease of antibodybinding capacity for peaks I and III. However, blocking of antibody combining sites by the synthetic peptide did not result in any loss of immunoreactivity for peak II.

\section{DISCUSSION}

Information concerning the biological activity of circulating PTH fragments has basic physiologic importance and practical implications for the interpretation of immunoassay results. If most of circulating PTH is biologically inactive (4), tissues are exposed to active hormone only after bursts of secretion by the parathyroid glands. This exposure would be brief since the half-life of glandular PTH approximates $20 \mathrm{~min}$ (12). On the other hand, if one or more PTH fragments possess biologic activity, tissues would be exposed to effective hormone for long periods after a particular stimulus to

TABLE II

Lack of Effect of Parathyroid Antibody on Activation of Renal Cortex Adenylate Cyclase by Peaks I and III

\begin{tabular}{|c|c|c|}
\hline & \multicolumn{2}{|c|}{$\begin{array}{c}\text { Cyclic } 3^{\prime}, 5^{\prime} \text {-AMP } \\
\text { accumulated } / 15 \mathrm{~min} \\
\text { per mg protein* }\end{array}$} \\
\hline & $\begin{array}{l}\text { Normal } \\
\text { chicken } \\
\text { serum }\end{array}$ & $\begin{array}{l}\text { Chicken } \\
\text { antiserum } \\
\text { to PTH }\end{array}$ \\
\hline Control§ & 98 & 133 \\
\hline Peak I & 336 & 336 \\
\hline Control & 105 & 112 \\
\hline Peak III & 490 & 357 \\
\hline Control & 105 & 133 \\
\hline РТH $(9.4 \mu \mathrm{g} / \mathrm{ml}) \|$ & 385 & 406 \\
\hline
\end{tabular}

* Each value represents the mean of closely agreeing duplicate samples.

$\ddagger$ Each test sample was preincubated for 5 days at $4^{\circ} \mathrm{C}$ with undiluted normal chicken serum or chicken antiserum to PTH.

$\S$ Control incubations contained equivalent amounts of fractionated hypoparathyroid serum.

|| Highly purified bovine PTH (Wilson Iaboratories, Chicago, III.).
TABLE III

Inhibition of Immunoreactivity of Human PTH Fragments by Synthetic 1-34 Amino Acids of Bovine PTH

\begin{tabular}{lccc} 
& \multicolumn{2}{c}{$\begin{array}{c}\text { Microliter equivalents of } \\
\text { standard serum } / \mathrm{m} \text { * }^{*}\end{array}$} & \\
\cline { 2 - 3 } & CH-824 & $\begin{array}{c}\text { CH-824 }+ \text { bovine } \\
1-34\end{array}$ & P value \\
\hline Peak I & $51 \pm 1.0$ & $24 \pm 0.8$ & $<0.001$ \\
Peak II & $92 \pm 2.8$ & $93 \pm 6.7$ & \\
Peak III & $95 \pm 5.5$ & $39 \pm 3.9$ & $<0.001$ \\
\hline
\end{tabular}

* Each value represents mean $\pm \mathrm{SE}$ for eight samples (two experiments, each performed in quadruplicate.)

PTH secretion. This is evident from the observation that PTH fragments have half-lives of the order of hours rather than minutes. In this scheme, the fragments would subserve the function of long-term stabilization of PTH effects (5).

Interpretation of immunoassays of PTH depends to a large extent on the biological activity of the fragments. If one or more immunoreactive fragment is biologically active, an assay would reflect exposure of end organs to specific stimulation. If the fragments are inert, immunoassays would provide only indirect information about parathyroid secretion.

The demonstration that peak III is active in renal tissue indicates that at least one target organ is subjected to prolonged exposure to active hormone. Whether this fragment is also active in other tissues remains to be explored. The presence of long-persisting, biologically, and immunologically active $\mathrm{PTH}$ fragment in the circulation explains why, according to reports from several laboratories, plasma or serum PTH may be normal in some patients with primary hyperparathyroidism $(13,14)$. Antisera having high affinity for glandular hormone but low affinity for peak III would be expected to yield assay results in the normal range in hyperparathyroidism even though the actual concentration of biologically active hormone is high.

The composition of peak III is unknown. Blocking experiments suggest that it contains antigenic determinants located in the $N$-terminal 1-34 amino acid residues of bovine PTH. The possibility that peak III is contaminated with substance capable of activating adenylate cyclase cannot be absolutely excluded but appears to be highly unlikely. The hypoparathyroid control fractionations provide strong evidence against nonparathyroid contaminants of peak III.

The observation that PTH antibodies do not block biological activity indicates that the biologically and immunologically active sites are distinct.

The difference between our results and those of others 
can be explained by differences in procedure of serum fractionation and methods of testing biological activity. Our active peak III constitutes approximately $25 \%$ of immunoreactivity in hyperparathyroid serum. It has not been described by others, presumably because use of concentrated samples in our system makes possible a better separation of fragments; in unconcentrated samples, separation of the 7,000-7,500 mol wt from the 4,500-5,000 mol wt peak may not be possible. Concentrating samples has the added advantage of yielding sufficient material for direct assay in the renal adenylate cyclase system. It has the drawback of possible artefactual generation of PTH fragments, but this possibility appears to be excluded by appropriate control experiments (1).

\section{ACKNOWLEDGMENTS}

The authors are grateful to Mrs. Antoinette Schenk and Mrs. Eva Ruiz for their excellent technical assistance.

This investigation was supported in part by the National Institutes of Health Grant No. 1R01 HE13715-02, the Heart Association of Broward County, a Chapter of the Florida Heart Association, and National Institutes of Health Grant No. AM08572.

\section{REFERENCES}

1. Canterbury, J. M., and E. Reiss. 1972. Multiple immunoreactive molecular forms of parathyroid hormone in human serum. Proc. Soc. Exp. Biol. Med. 140: 1393.

2. Habener, J. F., D. Powell, T. M. Murray, G. P. Mayer, and J. T. Potts, Jr. 1971. Parathyroid hormone: secretion and metabolism in vivo. Proc. Natl. Acad. Sci. U. S. A. 68: 2986.

3. Arnaud, C., R. Goldsmith, J. Bischoff, G. Sizemore, S. Oldham, and J. Larsen. 1972. Antibody specificity, im- munochemical heterogeneity, and the interpretation of measurements of plasma parathyroid hormone by radioimmunoassay. J. Clin. Invest. 51: 5a. (Abstr.)

4. Habener, J. F., G. V. Serge, D. Powell, T. M. Murray, and J. T. Potts, Jr. 1972. Immunoreactive parathyroid hormone in circulation of man. Nat. New Biol. 238 : 152.

5. Fisher, J. A., S. B. Oldham, G. W. Sizemore, and C. D. Arnaud. 1972. Calcium-regulated parathyroid hormone peptidase. Proc. Natl. Acad. Sci. U. S. A. 69: 2341.

6. Chase, L. R., and G. D. Aurbach. 1968. Renal adenyl cyclase: anatomically separate sites for parathyroid hormone and vasopressin. Science (Wash. D. C.). 159: 545.

7. Chase, L. R., and G. D. Aurbach. 1967. Parathyroid function and the renal excretion of $3^{\prime}, 5^{\prime}$-adenylic acid. Proc. Natl. Acad. Sci. 58: 518.

8. Lowry, O. H., N. J. Rosebrough, A. L. Farr, and R. J. Randall. 1951. Protein measurement with the Folin phenol reagent. J. Biol. Chem. 193: 265.

9. Krishna, G. B., B. Weiss, and B. B. Brodie. 1968. A simple, sensitive method for the assay of adenyl cyclase. J. Pharmacol. Exp. Ther. 163: 379.

10. Levey, G. S., and S. E. Epstein. 1969. Myocardial adenyl cyclase: activation by thyroid hormones and evidence for two adenyl cyclase systems. J. Clin. Invest. 48: 1663.

11. Reiss, E., and J. M. Canterbury. 1968. A radioimmunoassay for parathyroid hormone in man. Proc. Soc. Exp. Biol. Med. 128: 501.

12. Sherwood, L. M., G. P. Mayer, C. F. Ramberg, Jr., D. S. Kronfeld, G. D. Aurbach, and J. T. Potts, Jr. 1968. Regulation of parathyroid hormone secretion: proportional control by calcium, lack of effect of phosphate. Endocrinology. 83: 1043.

13. Arnaud, C. D., H. S. Tsao, and T. Littledike. 1971. Radioimmunoassay of human parathyroid hormone in serum. J. Clin. Invest. 50: 21.

14. Roof, B. S., B. Carpenter, D. J. Fink, and G. S. Gordan. 1971. Some thoughts on the nature of ectopic parathyroid hormones. Am. J. Med. 50: 686. 